Supporting Information for

\title{
Photochemically Crosslinked Quantum Well Ligands for 2D/3D Perovskite Photovoltaics with Improved Photovoltage and Stability
}

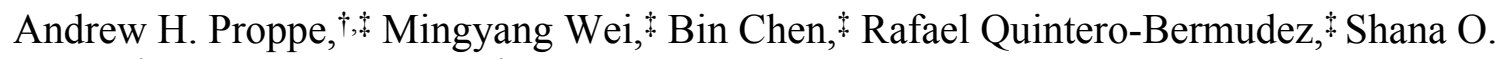
Kelley, ${ }^{\dagger} \S$ Edward H. Sargent ${ }^{\sharp *}$

† Department of Chemistry, University of Toronto, 80 St. George Street, Toronto, Ontario, Canada, M5S 3G4.

‡ The Edward S. Rogers Department of Electrical and Computer Engineering, University of Toronto, 10 King's College Road, Toronto, Ontario, Canada, M5S 3G4.

$\S$ Department of Pharmaceutical Sciences, Leslie Dan Faculty of Pharmacy, University of Toronto, Toronto, Ontario, Canada, M5S 3M2

\section{Contains:}

Methods \& Materials

Figures. S1 to S15 


\section{Materials}

All chemicals used are commercially available from Sigma-Aldrich (or otherwise specified) and were used without any additional purification steps: 4-Vinylbenzylamine (stabilized with MEHQ, >92.0\%, TCI (Product Number : V0101)), dimethylformamide anhydrous (DMF, 99\%), dimethylsulfoxide anhydrous (DMSO, 99.9\%), lead (II) iodide (from Alfa Aesar, 99.999\%, ultra dry), lead(II) bromide (from Alfa Aesar, 99.999\%), allylamine (98\%), hydroiodic acid (57 wt. \% in $\mathrm{H}_{2} \mathrm{O}$, distilled, stabilized, 99.95\%), methylammonium iodide (from Dyesol Inc., 99.9\%), methylammonium bromide (from Dyesol Inc., 99.9\%), formadinium iodide (from Dyesol Inc.), cesium iodide (99.999\%), phenethylammonium iodide (from Dyesol Inc.), chlorobenzene anhydrous, 2,2',7,7'-tetrakis-(N,N-di-pmethoxyphenylamine)9,9'-spirobifluorene (spiro-OMeTAD).

\section{Synthesis of 4-vinylbenzylammonium bromide and iodide salts}

$1 \mathrm{~g}$ of 4-vinylbenzylamine (VBA, $0.98 \mathrm{~mL}, 7.36 \mathrm{mmol}$, stored in a freezer prior to use) was added to $15-30 \mathrm{~mL}$ of cold isopropanol (cooled in an ice bath). $0.65 \mathrm{~mL}$ of a solution of $48 \% \mathrm{HBr}(6.62$ mmol) was added dropwise to the cooled VBA / isopropanol mixture. This mixture was left to react for 2 hours, slowly warming up to room temperature. The solvent was then evaporated under reduced pressure and the remaining white solid was left to dry for an addition 30 min under mild heating and vacuum (temperature was maintained at a maximum of $70^{\circ} \mathrm{C}$ ). The solid was then stirred in $\sim 20 \mathrm{~mL}$ diethyl ether for $10-15$ minutes before being filtered and washed five times with diethyl ether. This washed solid white powder was then recrystallized by dissolving in boiling isopropanol and subsequently re-precipitated with diethyl ether. The recrystallized solid was isolated via vacuum filtration, washed an addition three times with diethyl ether, and then held under vacuum for 16 hours before being brought into a nitrogen glovebox for storage and use. We performed ${ }^{1} \mathrm{H}$ NMR on the washed and recrystallized products to ensure that the vinyl groups remained unreacted after exposure to heat when drying and recrystallizing the solid. The same procedure was used for the analogous iodide salt, using a solution of 55\% HI instead.

\section{Preparation of perovskite precursor solutions}

Precursor solutions were prepared by dissolving mixtures of lead(II) iodide $\left(\mathrm{PbI}_{2}\right)$, lead(II) bromide $\left(\mathrm{PbBr}_{2}\right)$, methylammonium iodide (MAI), methylammonium bromide (MABr) 
formadinium iodide (FAI), cesium iodide (CsI), in a 4:1 mixture of DMF:DMSO. Precursors were mixed in the appropriate proportions to achieve a MAFACs perovskite composition of $\left(\mathrm{MA}_{0.95} \mathrm{Cs}_{0.05} \mathrm{PbBr}_{3}\right)_{0.15}\left(\mathrm{FA}_{0.95} \mathrm{Cs}_{0.05} \mathrm{PbI}_{3}\right)_{0.85}$ (more simply, $\left(\mathrm{MAPbBr}_{3}\right)_{0.15}\left(\mathrm{FAPbI}_{3}\right)_{0.85}$ where $5 \%$ of the MA and FA cations are substituted for Cs.

Example of a typical preparation for $1 \mathrm{~mL}$ of precursor solution with $\left[\mathrm{Pb}^{2+}\right]=1.4 \mathrm{M}$ : In a nitrogen glovebox, $548.6 \mathrm{mg}$ (1.19 mmol) of $\mathrm{PbI}_{2}, 77.1 \mathrm{mg}(0.21 \mathrm{mmol})$ of $\mathrm{PbBr}_{2}, 22.3 \mathrm{mg}(0.20 \mathrm{mmol})$ of MABr, $194.5 \mathrm{mg}(1.13 \mathrm{mmol})$ of FAI, $18.2 \mathrm{mg}(0.07 \mathrm{mmol})$ of CsI are dissolved in a 4:1 mixture of DMF:DMSO. This solution is heated to $70^{\circ} \mathrm{C}$, and stirred at this temperature for at least 2 hours before being cooled to room temperature, and filtered $(0.22 \mu \mathrm{m}, \mathrm{PTFE})$ into a new vial to be suitable for deposition.

\section{Deposition of 3D perovskite films}

$80 \mu \mathrm{L}$ of perovskite precursor solution was dropped onto a substrate for a two-step spinning procedure. The first step was $1000 \mathrm{rpm}$ for $5 \mathrm{~s}$ with an acceleration of $200 \mathrm{rpm} \mathrm{s}^{-1}$, followed by $4000 \mathrm{rpm}$ for $20 \mathrm{~s}$ with an acceleration of $800 \mathrm{rpm} \mathrm{s}^{-1} .150 \mu \mathrm{L}$ of chlorobenzene antisolvent is dropped onto the spinning substrate $15 \mathrm{~s}$ into the second spinning step. The substrate is then transferred onto a hotplate at $100^{\circ} \mathrm{C}$ to be annealed for $20 \mathrm{~min}$. For films that are treated with ligands to form 2D/3D perovskites, films are annealed instead for 10 minutes. This procedure is identical for depositing films on glass and on substrates for device fabrication. For films on glass, the substrates are first treated with oxygen plasma for 5 minutes before spin-coating the perovskite.

\section{Formation of 2D/3D perovskites on top surface}

Ligand solutions were prepared by dissolving $3-5 \mathrm{mg}$ of VBABr or VBAI salts in $1 \mathrm{~mL}$ of a 1:1 mixture of isopropanol and chlorobenzene. Rather than using pure isopropanol (the solvent component which is necessary to dissolve the salts), we mixed this chlorobenzene, an antisolvent for perovskite thin films, based on observations by Liang et al. that prolonged exposure to pure isopropanol can result in the partial dissolution of $\mathrm{PbI}_{2}$ thin films. ${ }^{1}$

$200-300 \mu \mathrm{L}$ of ligand solution is dynamically spin coated onto partially annealed 3D films at a spin speed of $4000 \mathrm{rpm}$ for 20 seconds. The films are then transferred onto a hot plate to anneal at $100^{\circ} \mathrm{C}$ in order to remove residual solvent and help $2 \mathrm{D}$ perovskite crystallization. For UV 
irradiation, the films are maintained at $70^{\circ} \mathrm{C}$, and a $4 \mathrm{~W}, 254 \mathrm{~nm}$ UV lamp was placed $\sim 1 \mathrm{~cm}$ from the film surface for 15 minutes.

\section{Synthesis of $n=1 \mathrm{PQWs},(\mathrm{VBA})_{2} \mathrm{PbI}_{4}$}

$115.3 \mathrm{mg}$ of $\mathrm{PbI}_{2}(0.25 \mathrm{mmol})$ and $130.5 \mathrm{mg}$ of VBAI $(0.50 \mathrm{mmol})$ are mixed in $0.5 \mathrm{~mL}$ of DMF (resulting in a solution with $\left[\mathrm{Pb}^{2+}\right]=0.5 \mathrm{M}$ ). This solution is stirred at $70^{\circ} \mathrm{C}$ for 2 hours, cooled to room temperature, filtered $(0.22 \mu \mathrm{m}, \mathrm{PTFE})$ and spin coated on cleaned glass slides at $4000 \mathrm{rpm}$ for $20 \mathrm{~s}$. Films are annealed at $100^{\circ} \mathrm{C}$ for 10 minutes, and UV irradiation was performed in the same manner as described for 2D/3D films.

\section{Photoluminescence measurements}

PL measurements were performed using a Horiba Fluorolog Time Correlated Single Photon Counting (TCSPC) system with photomultiplier tube detectors. A pulsed laser diode (374 nm, 110 - 140 ps pulse width) was used as excitation sources for steady-state and transient measurements. For transient and steady-state measurements, a $3200 \mathrm{~ns}$ period ( $0.28 \mathrm{~nJ}$ per pulse) was used to capture accurate lifetimes carrier lifetimes.

\section{Device fabrication}

Pre-patterned indium tin oxide (ITO, TFD Devices) coated glass substrates were sonicated in acetone and isopropanol sequentially for $30 \mathrm{~min}$. each before being dried under a flow of nitrogen gas. Titanium oxide $\left(\mathrm{TiO}_{2}\right)$ nanoparticles prepared according to reference 2 were deposited at 3000 $\mathrm{rpm}$ for $30 \mathrm{~s}$ with no ramping; this step is repeated twice. The substrates are then annealed at $150^{\circ} \mathrm{C}$ for $30 \mathrm{~min}$ in air, cooled, and then brought into a nitrogen glovebox. The perovskite layer is deposited as described above. After the perovskite layer is annealed and cooled, a solution of spiroOMeTad $(65 \mathrm{mg} / \mathrm{mL})$, doped with $20 \mu \mathrm{L} / \mathrm{mL}$ of tert-butylpyridine and $70 \mu \mathrm{L} / \mathrm{mL}$ of bis(trifluoromethane)sulfonimide lithium salt $(170 \mathrm{mg} / \mathrm{mL}$ in acetonitrile), is deposited by dynamically spinning at $4000 \mathrm{rpm}$ for 20s. A $120 \mathrm{~nm}$ Au contact are deposited by electron-beam evaporation at a rate of $1.5 \AA \mathrm{s}^{-1}$.

\section{Device testing}

The current density-voltage $(J-V)$ characteristics were measured using a Keithley 2400 source meter under illumination from a solar simulator (Newport, Class A) with a light intensity of 100 
$\mathrm{mW} \mathrm{cm}{ }^{-2}$ (checked with a calibrated reference solar cell from Newport). Unless otherwise stated, the $J-V$ curves were all measured in a nitrogen atmosphere with a scanning rate of $100 \mathrm{mV} \mathrm{s}^{-1}$ (voltage step of $20 \mathrm{mV}$ and delay time of $200 \mathrm{~ms}$ ). The active area was determined by the aperture shade mask $\left(0.049 \mathrm{~cm}^{2}\right.$ for small-area devices $)$ placed in front of the solar cell. A spectral mismatch factor of 1 was used for all $J-V$ measurements. The dark long-term stability assessment of solar cells was carried out by repeating the $J-V$ characterizations over various times ( $\sim 1$ week apart each). The devices were stored in a cabinet with dry air with relative humidity between 20 and $30 \%$. The chamber containing the cells for testing were purged with and maintained under nitrogen flow during the measurements.

For operational stability measurements at maximum power point (MPP), the device testing chamber was left under ambient conditions. Solar cells were fixed at the MPP voltage, $V_{M P P}$ (determined from $J-V$ sweeps in both scanning directions) and current output was tracked over time.

Transient photovoltage measurements were carried out according to reference 3 .

\section{Scanning Electron Microscopy (SEM)}

SEM images were collected in secondary electron mode by a Hitachi SU5000. It was operated at a voltage of $3 \mathrm{kV}$ with spot size of 3 and intensity of 20 .

\section{Attenuated Total Reflection (ATR) Fourier Transform Infrared Spectroscopy (FTIR)}

ATR-FTIR measurements were carried out on a Thermo Scientific iS50 with a spectral range 4600 $-50 \mathrm{~cm}^{-1}$, equipped with an ATR accessory.

\section{Grazing Incidence Wide-Angle X-ray Scattering (GIWAXS)}

GIWAXS measurements were conducted at the Hard X-ray MicroAnalysis (HXMA) beamline of the Canadian Light Source (CLS). An energy of $17.998 \mathrm{keV}(\lambda=0.6888 \AA)$ was selected using a Si(111) monochromator. Patterns were collected on a SX165 CCD camera (Rayonix) placed at a distance of $157 \mathrm{~mm}$ from the sample. A lead beamstop was used to block the direct beam. Images were calibrated using LaB6 and processed via the Nika software package (ref 4) and the GIXSGUI MATLAB plug-in (ref 5). 


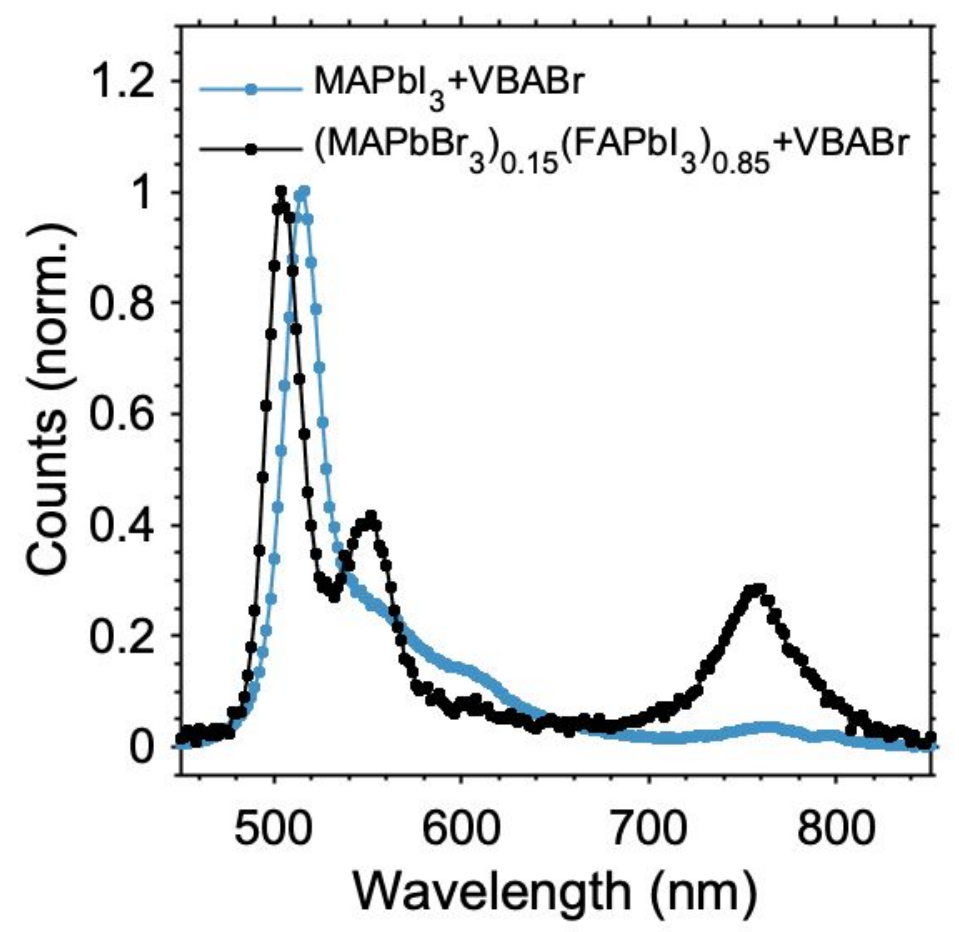

Figure S1. Photoluminescence spectra for films of $\mathrm{MAPbI}_{3}+\mathrm{VBABr}$ and $\left(\mathbf{M A P b B r}_{3}\right)_{0.15}\left(\mathbf{F A P b I}_{3}\right)_{0.85}+\mathbf{V B A B r}$. Films were photoexcited at a wavelength of $374 \mathrm{~nm}$. Treating the $\mathrm{MAPbI}_{3}$ surface with a $3 \mathrm{mgmL}^{-1}$ solution of $\mathrm{VBABr}$ in isopropanol / chlorobenzene results in a $2 \mathrm{D} / 3 \mathrm{D}$ heterostructure where the top layer consists primarily of $n=1$ iodine $2 \mathrm{D}$ perovskites as evidenced by the emission maximum at $516 \mathrm{~nm}$. In the $\left(\mathrm{MAPbBr}_{3}\right)_{0.15}\left(\mathrm{FAPbI}_{3}\right)_{0.85}$ $+\mathrm{VBABr} 2 \mathrm{D} / 3 \mathrm{D}$ film (which is used exclusively throughout this study unless otherwise stated), the $n=1$ peak is slightly blueshifted. We conclude that this blueshifting arises due to the composition of the 3D perovskite itself, and not due to bromine from the ligand solution (since the $n=1$ emission from the $2 \mathrm{D}$ perovskites atop the $\mathrm{MAPbI}_{3}$ film are unshifted relative to normal emission of pure iodine 2D perovskites, see references 6,7 ). 


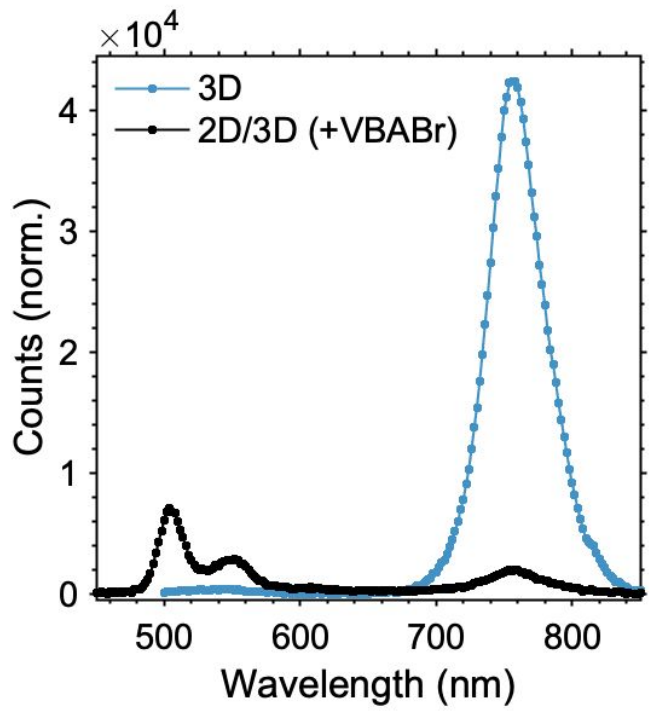

Figure S2. Unnormalized photoluminescence spectra for 2D/3D and 3D films. Experiments were performed under identical conditions, indicating that the overall radiative recombination in the $2 \mathrm{D} / 3 \mathrm{D}$ films is less than that of the $3 \mathrm{D}$ film. Films were photoexcited at a wavelength of 374 nm. 
a

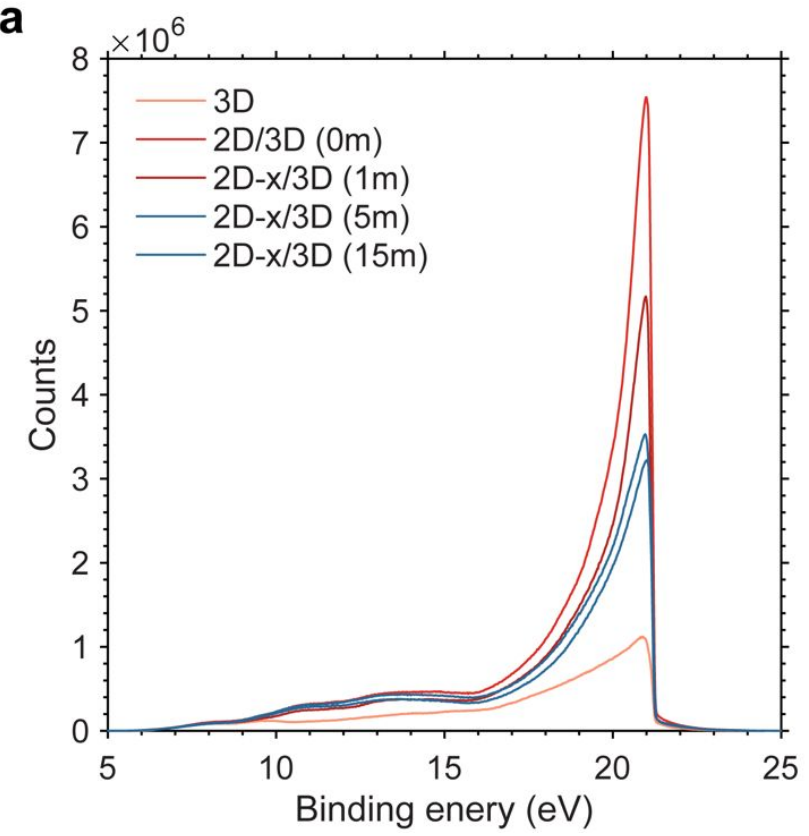

b

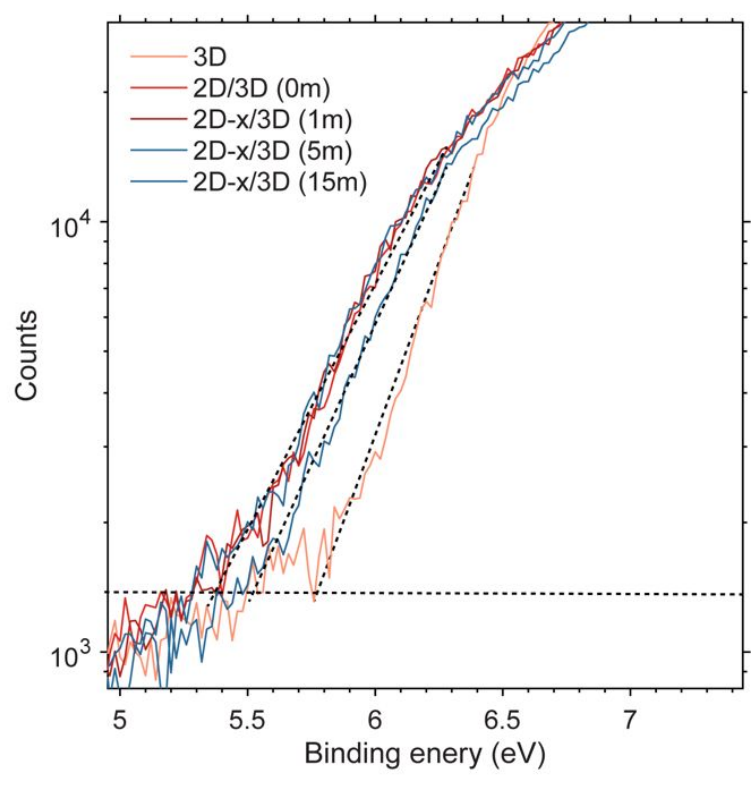

Figure S3. UPS spectra for 3D-only and 2D-x/3D films with various UV exposure times. The counts for the 3D-only film reach the noise floor at approximately $5.7 \mathrm{eV}$, whereas the counts for the $2 \mathrm{D}-\mathrm{x} / 3 \mathrm{D}$ films cross at $\sim 5.4 \mathrm{eV}$. 
a

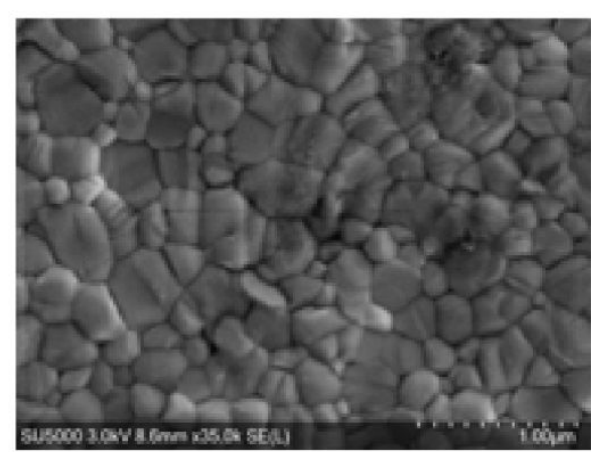

C

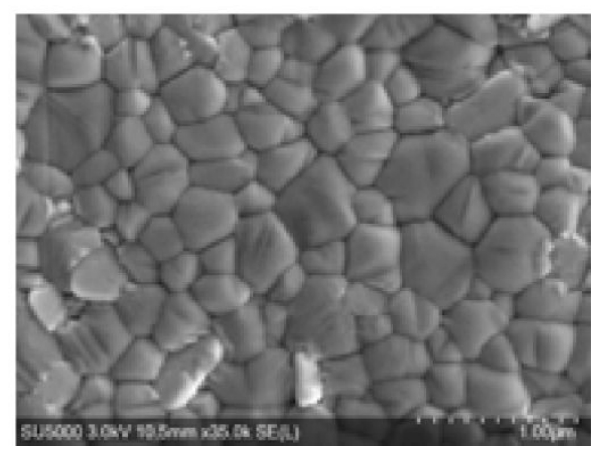

b

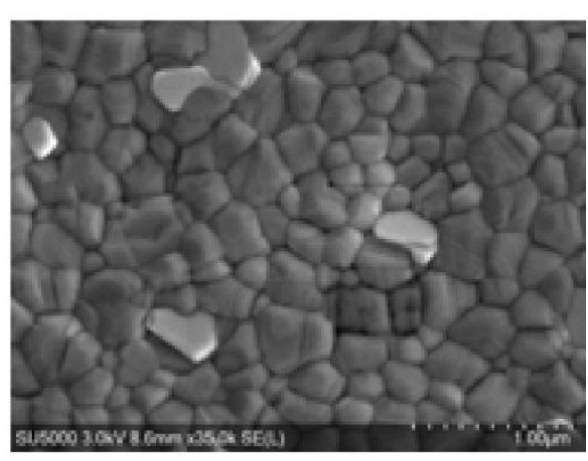

d

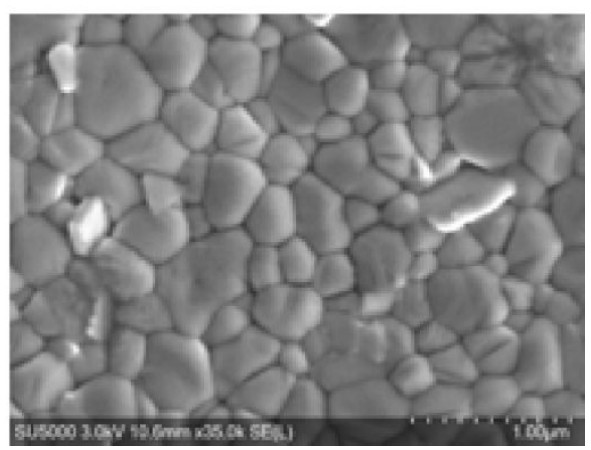

Figure S4. SEMS for 3D, 2D/3D and 2D-x/3D films. (a) 3D-only film, (b) after ligand treatment with no annealing, (c) after ligand treatment with $70^{\circ} \mathrm{C}$ annealing for 5 minutes $(2 \mathrm{D} / 3 \mathrm{D})$ and (d) after ligand treatment with $70^{\circ} \mathrm{C}$ annealing and UV exposure for 15 minutes (2D-x/3D). 


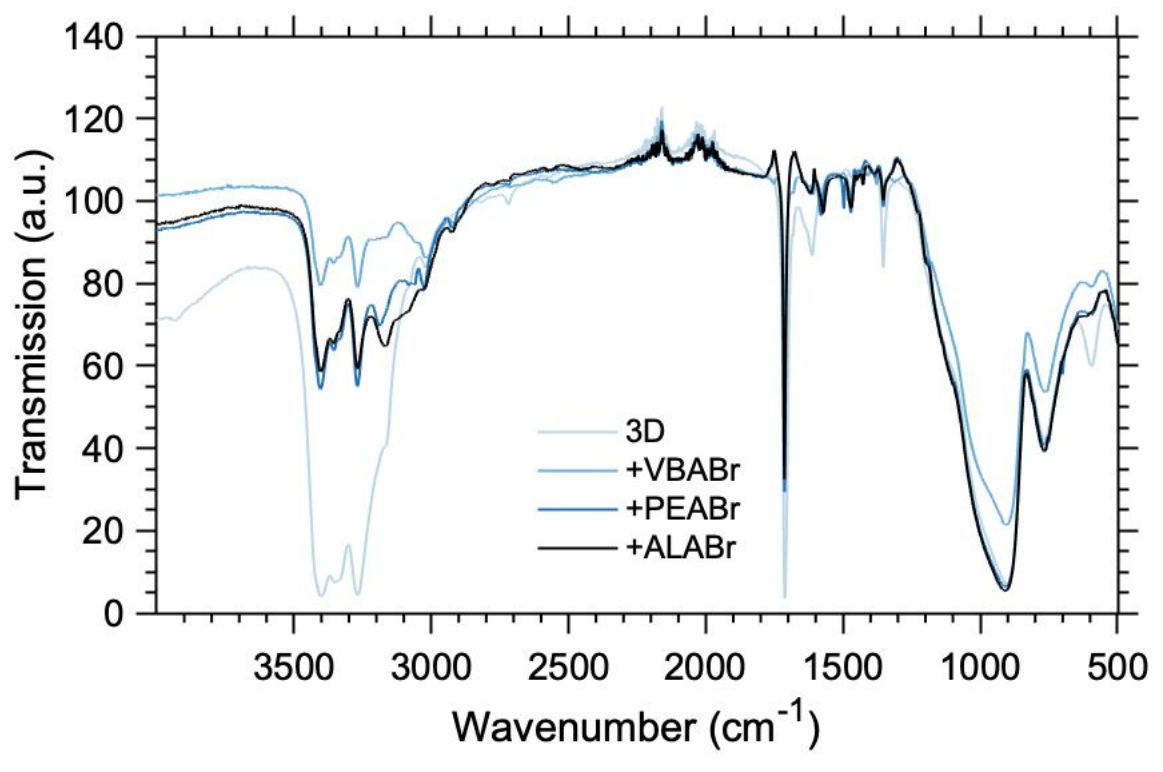

Figure S5. ATR-FTIR spectra of 2D/3D perovskites with various ligands. 3D films were treated with solutions of 4-vinylbenzylammonium bromide ( $\mathrm{VBABr}$ ), phenethylammonium bromide (PEABr) or allylammonium bromide (ALABr) dissolved in a 1:1 mixture of isopropanol and chlorobenzene with a concentration of $5 \mathrm{mgmL}^{-1}$. This solution was soaked on top of the film for 5 seconds before being spin coated off (at $4000 \mathrm{rpm}$ ) in order to obtain sufficient observable signal in ATR-FTIR measurements. 


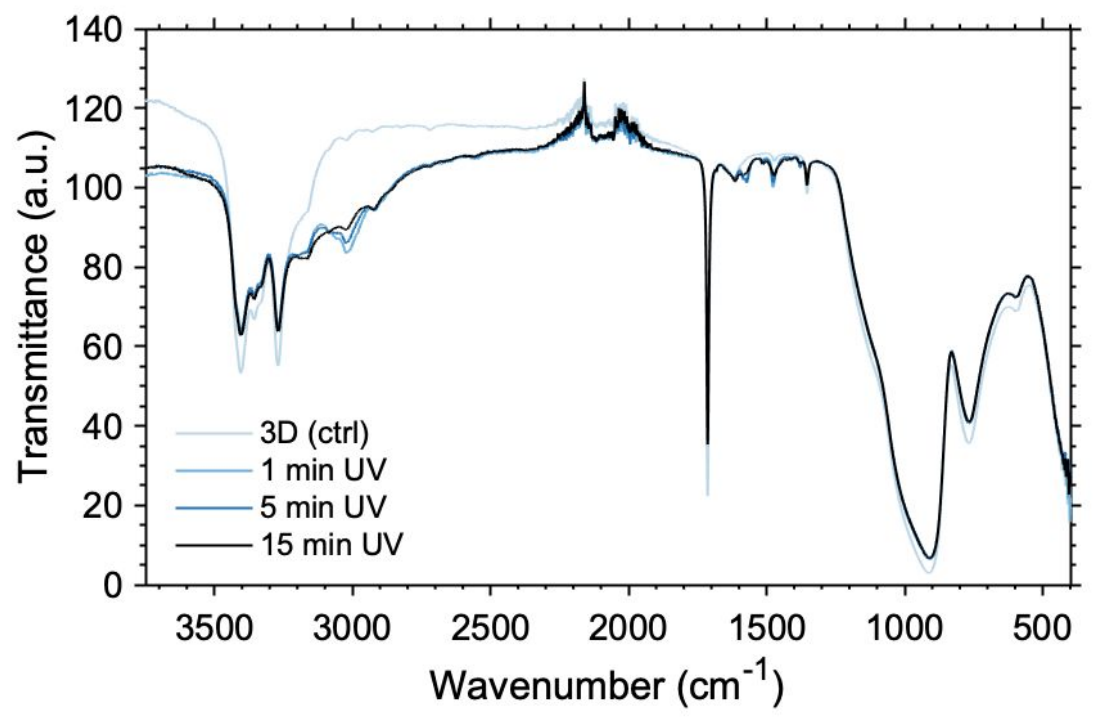

Figure S6. Full ATR-FTIR spectra of 2D/3D perovskites with varying UV exposure times. Spectrum for a 3D-only film control is plotted alongside spectra for 2D/3D films. 


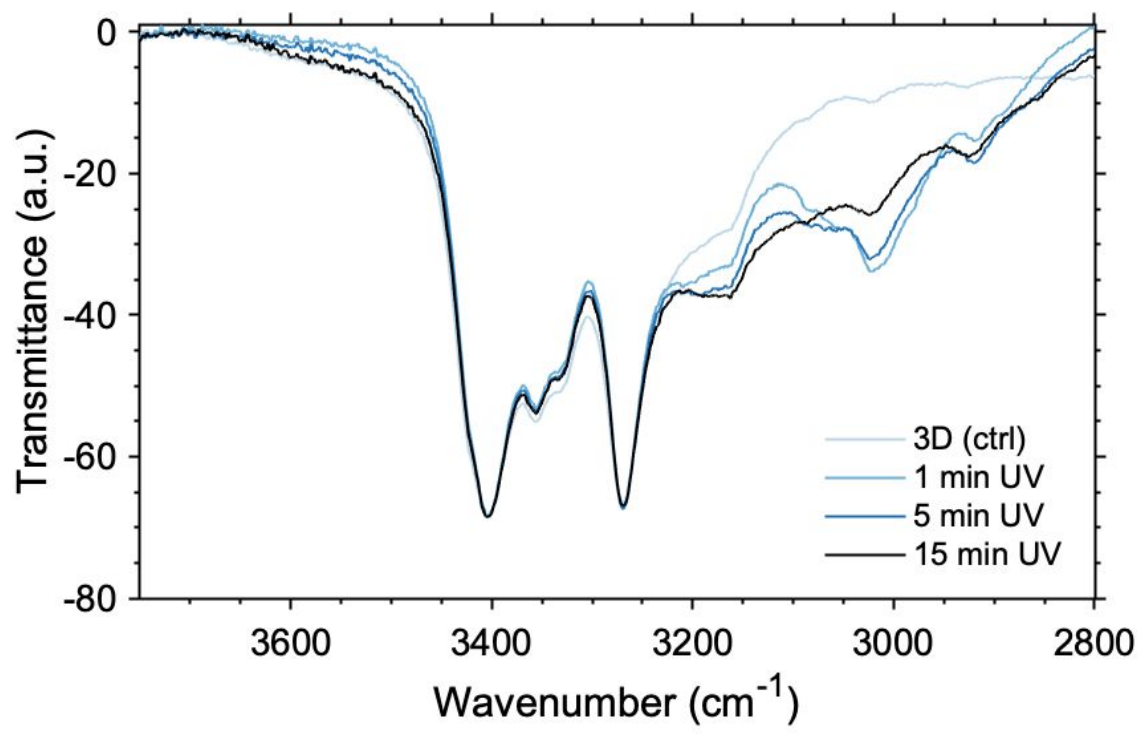

Figure S7. ATR-FTIR spectra for 3D and UV-treated 2D/3D perovskites in high energy region. A similar, but less prominent, increase of the broad signal between $3400-3600$ is observed for the 2D/3D films. Films were normalized at their lowest transmission peak (here, the peak at $\sim 3400 \mathrm{~cm}^{-1}$ ) for comparison. 


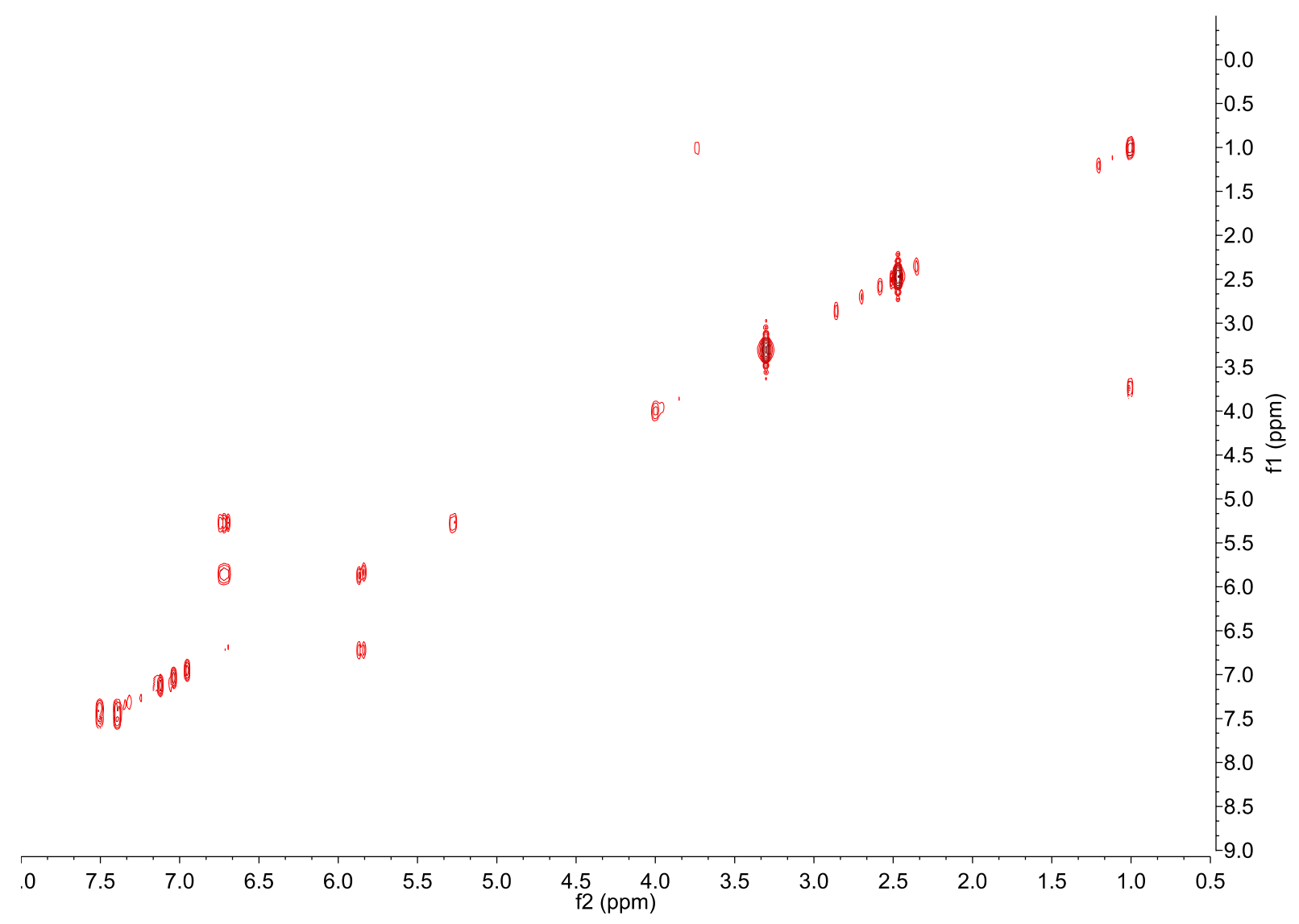

Figure S8. ${ }^{1} \mathrm{H}-{ }^{1} \mathrm{H}$ COSY NMR spectrum for redissolved UV-treated $\boldsymbol{n}=\mathbf{1}$ films. Peaks between 6.8 and $7.2 \mathrm{ppm}$ belong to aromatic protons of the photoproduct. No crosspeaks are discernible between these protons and other protons within the molecule, indicating that no new bonds have been formed on the aromatic sites of the molecule. 


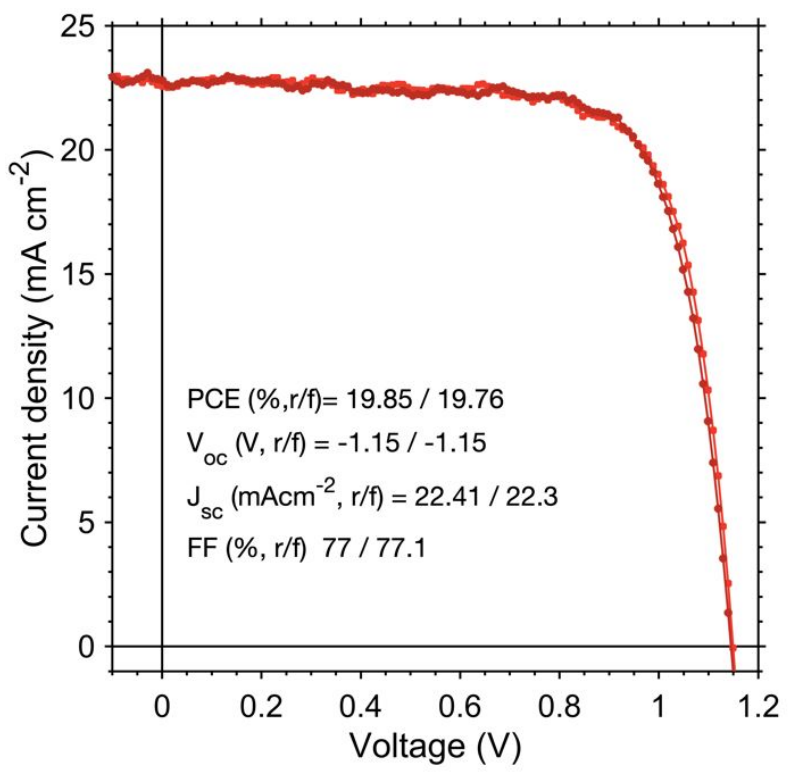

Figure S9. Current-voltage curves for a 2D/3D uncrosslinked device. Device fabrication and measurements were carried out in the same conditions as the $3 \mathrm{D}$ and $2 \mathrm{D}-\mathrm{x} / 3 \mathrm{D}$ devices. Films were annealed at $100^{\circ} \mathrm{C}$ for 10 minutes after treatment with $\mathrm{VBABr}$ ligand and not exposed to any UV irradiation. 

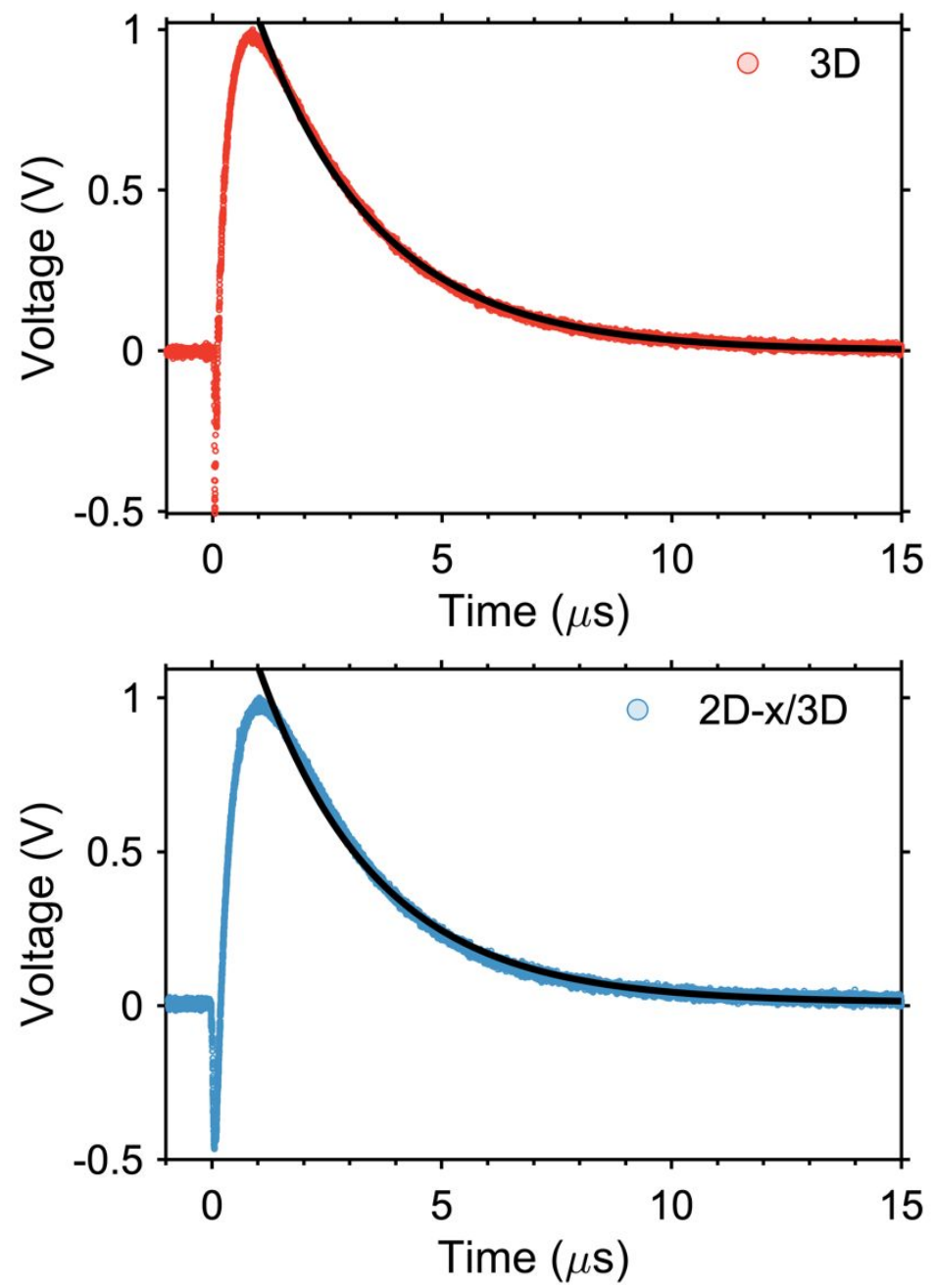

Figure S10. Normalized photovoltage transients for 3D and 2D-x/3D devices. To obtain fits, we first subtracted the average of the first 50 time points (i.e. times before laser photoexcitation) to establish a common baseline for both devices, and then normalized the transients to 1 at their highest amplitude. Monoexponential first were obtain by starting the fit when the transient reaches 1. Superposed normalized transients are in Fig. S9 below. 


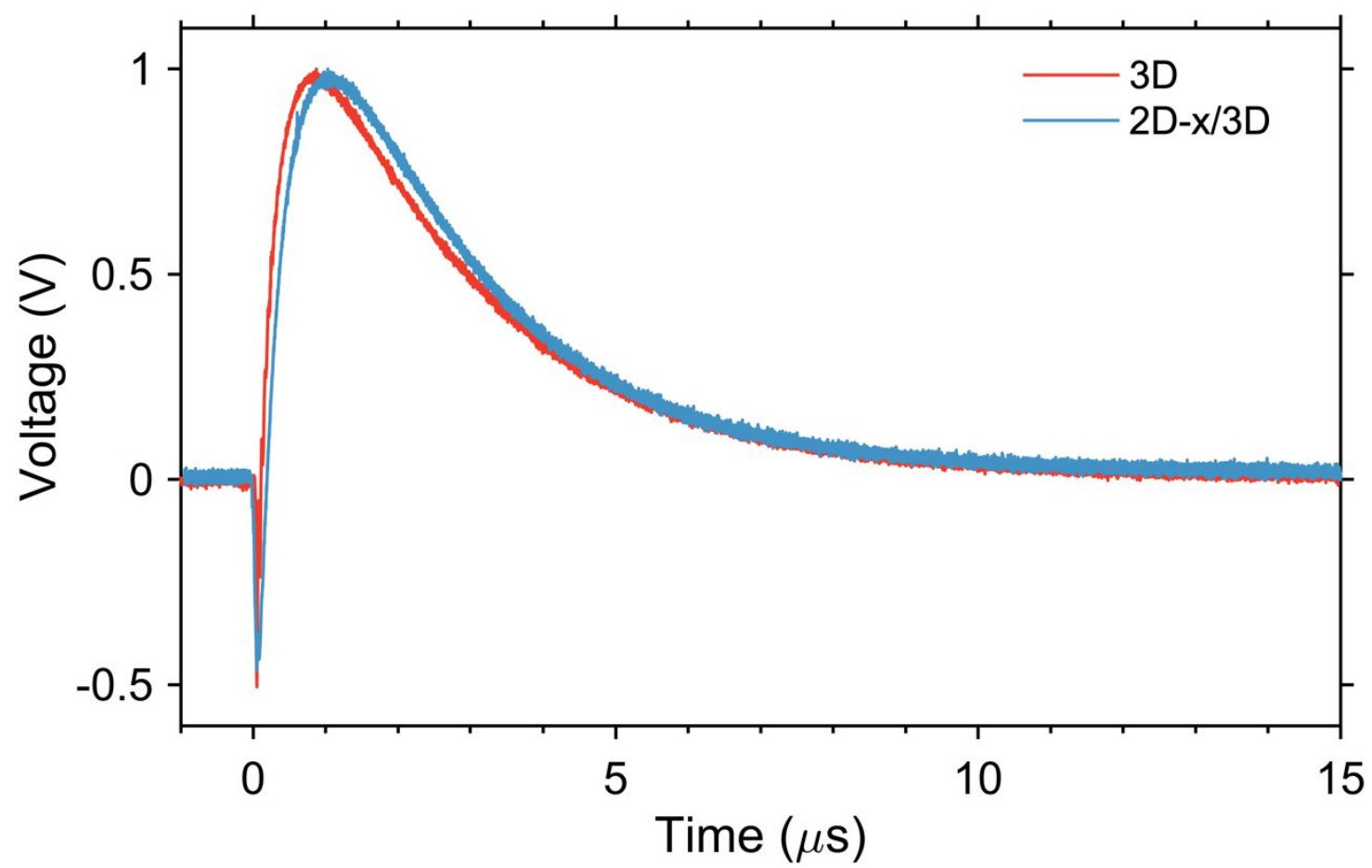

Figure S11. Superposed normalized photovoltage transients for $3 D$ and $2 D-x / 3 D$ devices. A slightly longer lifetime is observed for the $2 \mathrm{D}-\mathrm{x} / 3 \mathrm{D}$ devices. 

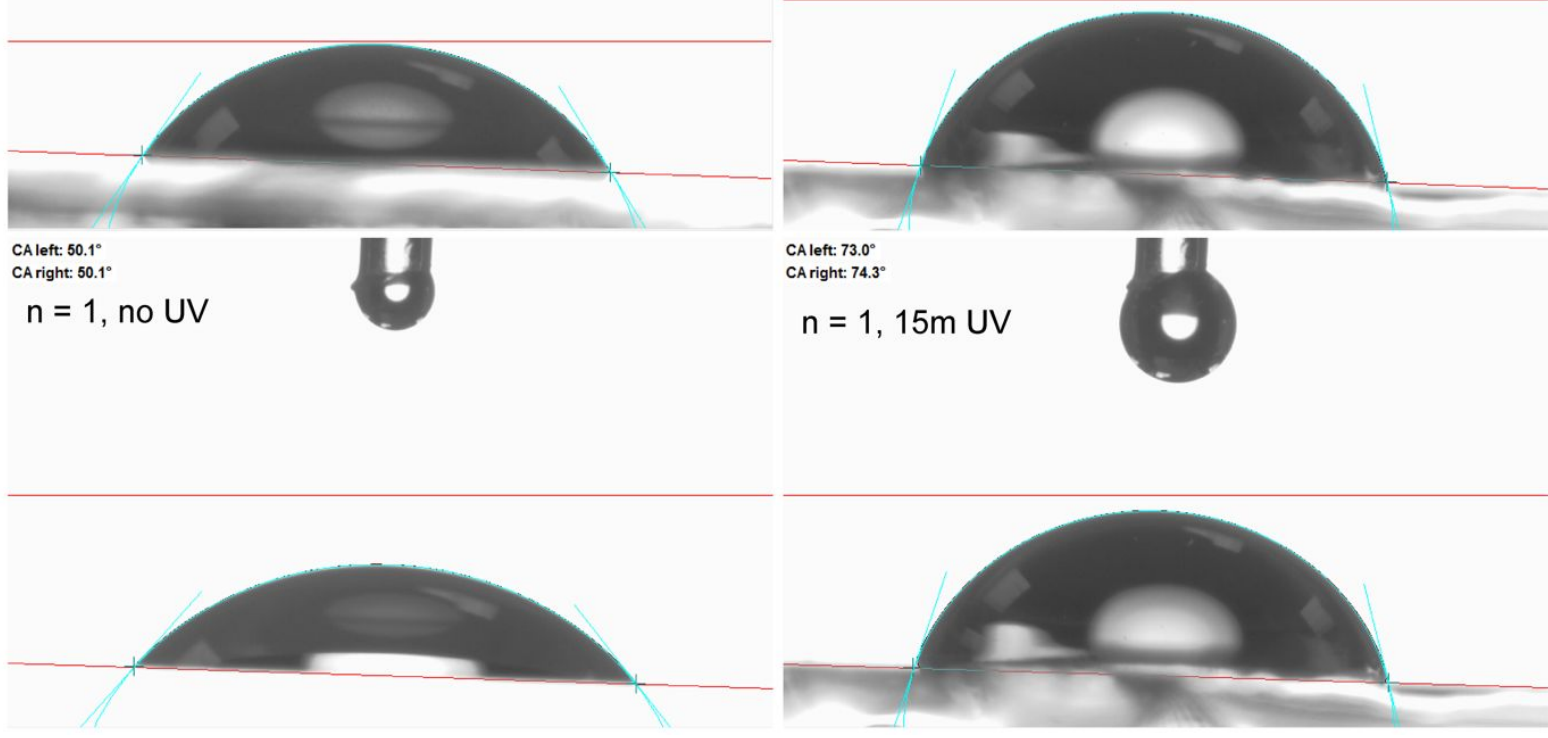

Figure S12. Water contact angle measurements for 2D/3D and $n=1(\mathrm{VBA})_{2} \mathrm{PbI}_{4}$ films before and after $\mathbf{U V}$ treatment. We find that the contact angle with water is increased from $57^{\circ}$ to $\sim 73^{\circ}$ after the UV treatment for the $2 \mathrm{D} / 3 \mathrm{D}$ perovskites. We also find that this effect is slightly more pronounced when the same measurement is performed on pure films of $n=1(\mathrm{VBA})_{2} \mathrm{PbI}_{4}$, where the water contact angle increases from $50^{\circ}$ to $74^{\circ}$. These measurements support our hypothesis that the increased hydrophobicity of the crosslinked photoproduct helps to prevent water ingress, increasing film stability in ambient conditions. 


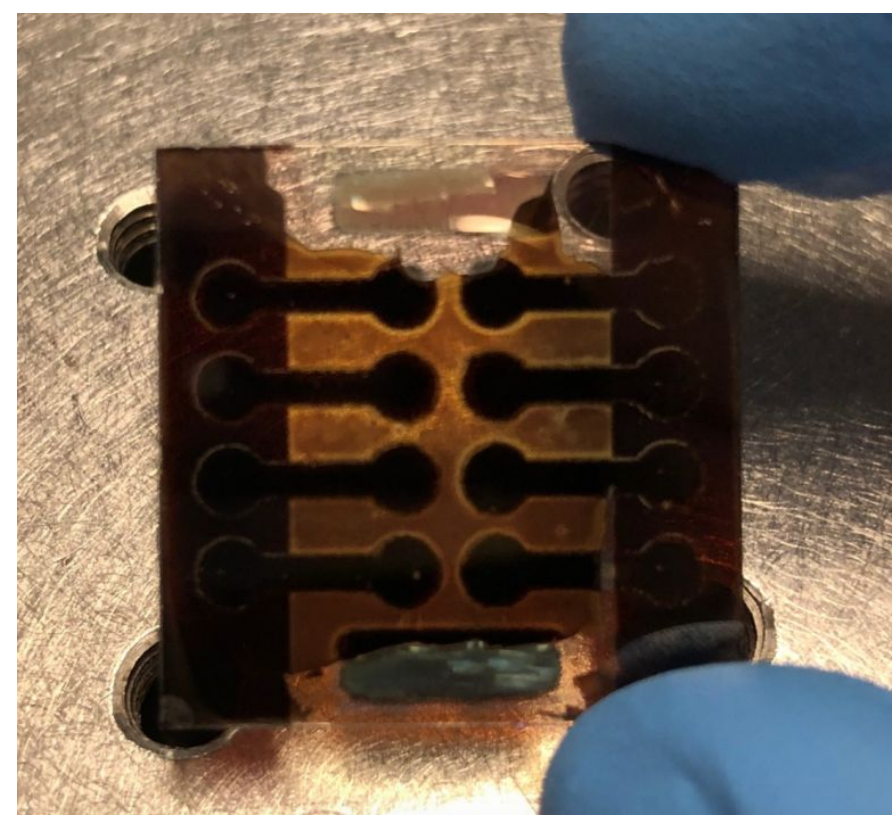

Figure S13. Pixel edge degradation in an aged device. Example of a typical device, aged for $>3$ months, in the same ambient conditions as the other devices used in this study. It is clearly observed that the edges surrounding the device pixels degrade due to atmospheric moisture, effectively decreasing the active area of the pixel with time and lower photocurrent. 

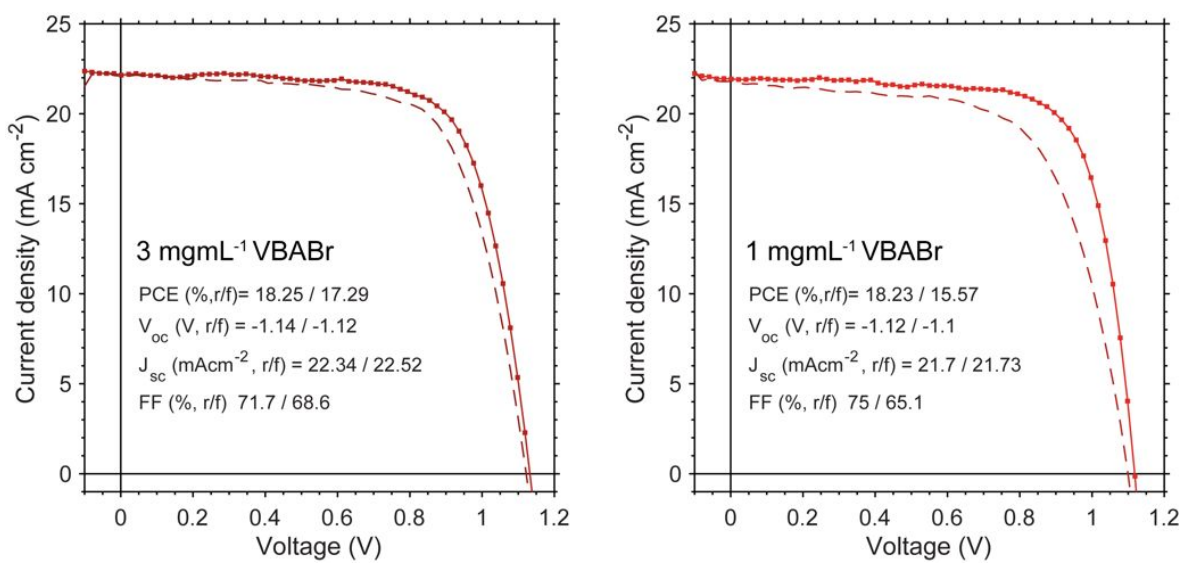

Fig. S14. $J-V$ curves for $2 \mathrm{D}-\mathrm{x} / 3 \mathrm{D}$ devices prepared using $1 \mathrm{mgmL}^{-1}$ and $3 \mathrm{mgmL}^{-1}$ solutions of VBABr. While $V_{O C}$ and $J_{S C}$ are increased (relative to the 3D-only film) for both devices, the 3 $\mathrm{mgmL}^{-1}$ device more effectively eliminates hysteresis and thus exhibits a higher overall efficiency than the $1 \mathrm{mgmL}^{-1}$ device. 


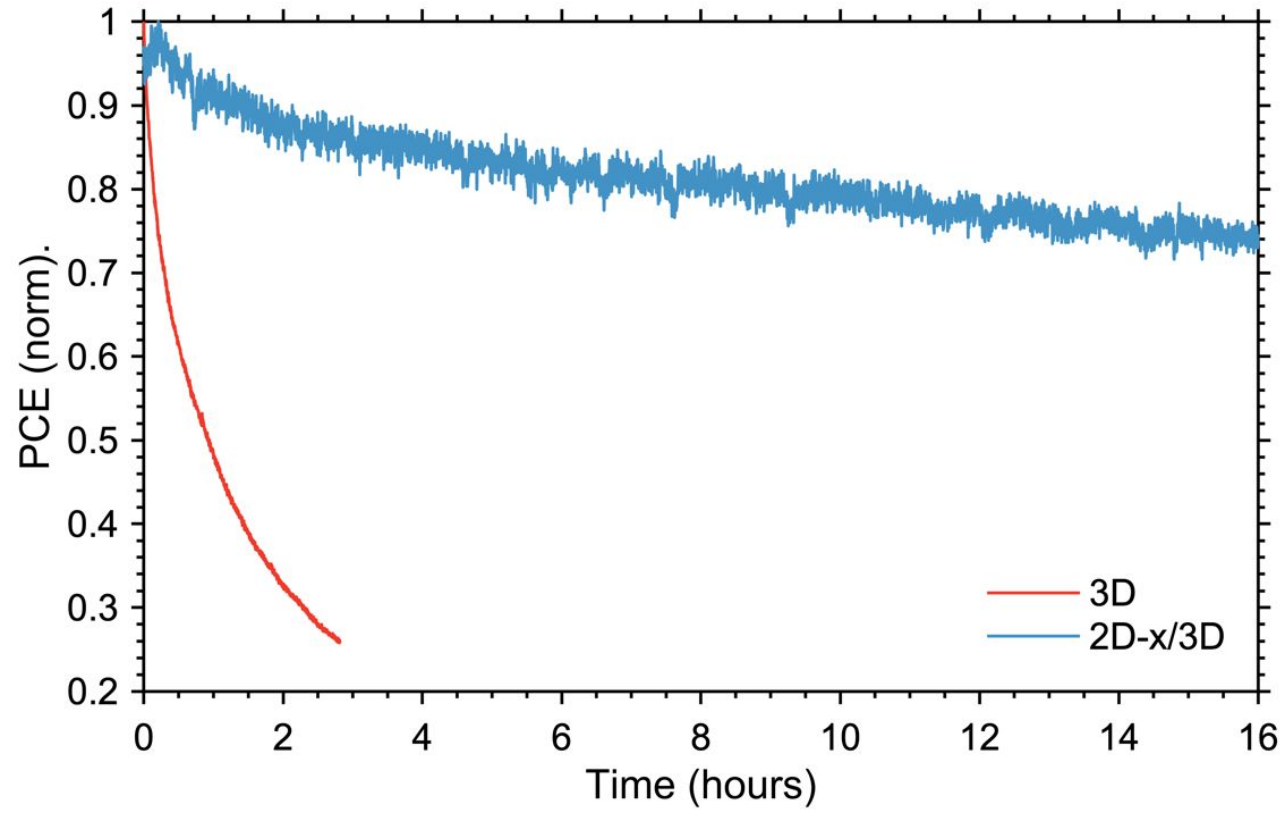

Figure S15. Maximum power point tracking of the 3D-only and 2D-x/3D devices. Devices were aged in full AM1.5G illumination (i.e. no cut-off filters used) in ambient temperature and atmospheric conditions $\left(\sim 25^{\circ} \mathrm{C}\right.$ and $30 \%$ relative humidity). 


\begin{tabular}{c|c|c|c|c}
$\begin{array}{c}\text { Sample \& } \\
\text { condition }\end{array}$ & A1 & A2 & T1 (ns) & T2 (ns) \\
\hline 3D (front) & 1 & - & 842 & - \\
\hline 3D (back) & 1 & - & 839 & - \\
\hline 2D/3D (front) & 0.6 & 0.4 & 51 & 480 \\
\hline 2D/3D (back) & 0.35 & 0.8 & 35 & 827
\end{tabular}

Table S1. TCSPC Mono- and biexponential fits for front / back excitation of 3D-only and 2D-x/3D films. A photoexcitation wavelength of $374 \mathrm{~nm}$ was used for all experiments. 


\begin{tabular}{|c|c|c|c|c|c|c|}
\hline \multicolumn{7}{|c|}{$3 \mathrm{D}$} \\
\hline Ageing time (hours) & 48 & 288 & 456 & 624 & 960 & 2300 \\
\hline PCE (\%) & 17.736 & 16.941 & 14.850 & 14.092 & 12.023 & 5.351 \\
\hline PCE $\sigma(\%)$ & 0.848 & 1.023 & 0.558 & 0.336 & 0.707 & 1.758 \\
\hline $\mathrm{V}_{\text {oc }}(\mathrm{V})$ & 1.119 & 1.139 & 1.126 & 1.105 & 1.056 & 1.045 \\
\hline $\mathrm{V}_{\text {oc }} \sigma(\mathrm{V})$ & 0.008 & 0.009 & 0.006 & 0.027 & 0.024 & 0.029 \\
\hline $\mathrm{J}_{\text {sc }}\left(\mathrm{mAcm}^{-2}\right)$ & 21.690 & 21.894 & 18.790 & 19.737 & 18.895 & 7.815 \\
\hline $\mathrm{J}_{\text {sc }} \sigma\left(\mathrm{mAcm}^{-2}\right)$ & 0.715 & 0.166 & 0.560 & 1.444 & 0.434 & 1.709 \\
\hline $\mathrm{FF}(\%)$ & 73.060 & 67.920 & 70.225 & 64.833 & 60.250 & 64.444 \\
\hline $\mathrm{FF} \sigma(\%)$ & 4.323 & 3.406 & 1.795 & 3.917 & 2.369 & 4.842 \\
\hline
\end{tabular}

\begin{tabular}{|c|c|c|c|c|c|c|}
\hline \multicolumn{7}{|c|}{$2 \mathrm{D}-\mathrm{x} / 3 \mathrm{D}$} \\
\hline Ageing time (hours) & 48 & 288 & 456 & 624 & 960 & 2300 \\
\hline PCE (\%) & 19.489 & 19.097 & 19.175 & 19.794 & 20.385 & 17.739 \\
\hline PCE $\sigma(\%)$ & 0.650 & 0.228 & 0.179 & 0.248 & 0.675 & 0.429 \\
\hline $\mathrm{V}_{\text {oc }}(\mathrm{V})$ & 1.165 & 1.178 & 1.182 & 1.200 & 1.202 & 1.174 \\
\hline $\mathrm{V}_{\text {oc }} \sigma(\mathrm{V})$ & 0.010 & 0.002 & 0.003 & 0.001 & 0.003 & 0.009 \\
\hline $\mathrm{J}_{\mathrm{sc}}\left(\mathrm{mAcm}^{-2}\right)$ & 22.018 & 21.568 & 21.125 & 21.441 & 21.507 & 20.883 \\
\hline $\mathrm{J}_{\mathrm{sc}} \sigma\left(\mathrm{mAcm}^{-2}\right)$ & 0.564 & 0.599 & 0.513 & 0.683 & 0.153 & 0.633 \\
\hline $\mathrm{FF}(\%)$ & 0.760 & 0.752 & 0.769 & 0.770 & 0.789 & 0.724 \\
\hline $\mathrm{FF} \sigma(\%)$ & 0.013 & 0.025 & 0.024 & 0.033 & 0.026 & 0.010 \\
\hline
\end{tabular}

\begin{tabular}{|c|c|c|}
\hline \multicolumn{3}{|c|}{$2 \mathrm{D} / 3 \mathrm{D}(\mathrm{No}$ UV) } \\
\hline Ageing time (hours) & 48 & 2300 \\
\hline PCE $(\%)$ & 19.452 & 14.324 \\
\hline PCE $\sigma(\%)$ & 0.447 & 0.555 \\
\hline $\mathrm{V}_{\text {oc }}(\mathrm{V})$ & 1.157 & 1.160 \\
\hline $\mathrm{V}_{\text {oc }} \sigma(\mathrm{V})$ & 0.004 & 0.007 \\
\hline $\mathrm{J}_{\mathrm{sc}}\left(\mathrm{mAcm}^{-2}\right)$ & 22.190 & 17.776 \\
\hline $\mathrm{J}_{\mathrm{sc}} \sigma\left(\mathrm{mAcm}^{-2}\right)$ & 0.653 & 0.525 \\
\hline $\mathrm{FF}(\%)$ & 75.780 & 69.520 \\
\hline $\mathrm{FF} \sigma(\%)$ & 0.870 & 3.679 \\
\hline
\end{tabular}

Table S2. Photovoltaic figures of merit versus ageing time for 3D, 2D-x/3D and 2D/3D devices. Tabulated values are taken from the average of 5 devices. Standard deviation is notated as $\sigma$. 


\section{References}

(1) Liang, K.; Mitzi, D. B.; Prikas, M. T. Synthesis and Characterization of Organic-Inorganic Perovskite Thin Films Prepared Using a Versatile Two-Step Dipping Technique. Chem. Mater. 1998, 10 (1), 403-411. https://doi.org/10.1021/cm970568f.

(2) Tan, H.; Jain, A.; Voznyy, O.; Lan, X.; García de Arquer, F. P.; Fan, J. Z.; QuinteroBermudez, R.; Yuan, M.; Zhang, B.; Zhao, Y.; et al. Efficient and Stable SolutionProcessed Planar Perovskite Solar Cells via Contact Passivation. Science 2017, 355 (6326), 722-726. https://doi.org/10.1126/science.aai9081.

(3) Shao, Y.; Yuan, Y.; Huang, J. Correlation of Energy Disorder and Open-Circuit Voltage in Hybrid Perovskite Solar Cells. Nat. Energy 2016, 1 (1), 15001. https://doi.org/10.1038/nenergy.2015.1.

(4) Ilavsky, J. Nika: Software for Two-Dimensional Data Reduction. J. Appl. Crystallogr. 2012, 45 (2), 324-328. https://doi.org/10.1107/S0021889812004037.

(5) Jiang, Z. GIXSGUI: A MATLAB Toolbox for Grazing-Incidence X-Ray Scattering Data Visualization and Reduction, and Indexing of Buried Three-Dimensional Periodic Nanostructured Films. J. Appl. Crystallogr. 2015, 48 (3), 917-926. https://doi.org/10.1107/S1600576715004434.

(6) Weidman, M. C.; Seitz, M.; Stranks, S. D.; Tisdale, W. A. Highly Tunable Colloidal Perovskite Nanoplatelets through Variable Cation, Metal, and Halide Composition. ACS Nano 2016, 10 (8), 7830-7839. https://doi.org/10.1021/acsnano.6b03496.

(7) Proppe, A. H.; Elkins, M. H.; Voznyy, O.; Pensack, R. D.; Zapata, F.; Besteiro, L. V.; Quan, L. N.; Quintero-Bermudez, R.; Todorovic, P.; Kelley, S. O.; et al. Spectrally Resolved Ultrafast Exciton Transfer in Mixed Perovskite Quantum Wells. J. Phys. Chem. Lett. 2019, 10 (3), 419-426. https://doi.org/10.1021/acs.jpclett.9b00018. 